\title{
Confidence in conditions of social uncertainty
}

\author{
Vera Orlova ${ }^{1, *}$, Irina Sokolovskaya $^{2}$ \\ ${ }^{1}$ Tomsk State University of Control Systems and Radioelectronics, Russia \\ ${ }^{2} \mathrm{GUU}$ management, Russia
}

\begin{abstract}
Relevance is determined by the riskogennostju social, political, economic, social and cultural living conditions of Russians, growing uncertainty, fragmenarnostju the functioning of many social institutions. Relevance also lies in the intensity of the negative development orientations of youth as a result of the socio-economic changes and the growing public controversy, resulting in loss of life smysloobrazujushhih ideals, loss of confidence, changing values in public and individual consciousness. The problem of trust/distrust of youth to social agents, personal safety, selfactualization become relevant. Aggressive behaviour becomes the norm of the time. The role of trust as one of the most important factors in the implementation of dialogue in society. Prerequisites for the actualization of the destructive problems are complex and diverse in many respects, part of the Russian society and the socio-economic and political contradictions. The novelty is that the necessity of an interdisciplinary approach in the study of the phenomenon of "trust"; on the basis of a theoretical and comparative analysis of the factors forming confidence as conditions for social dialogue shows that supports socio-cultural situation in the society. Category "trust/distrust" appeared to be integrative, structural and properties of multicomponent, developing and undergoes a transformation.
\end{abstract}

\section{Introduction}

In the conditions of social changes in modern Russia, an active foreign policy to counter extremism and terrorism, the number of young people is growing, showing the features of militant narrow-mindedness, "intolerance of others," radical views. In modern domestic sociological science there is no clear concept of extremism. Neither in the philosophical nor in the English sociological dictionary there is a concept of "extremism." A possible search strategy is to adapt certain provisions of theories of an average level of sociological knowledge, as well as theories developed in the framework of other social disciplines (jurisprudence, psychology, history, political science, etc.) (De la terreur à l'extrême violence Petar Bojanić et Guillaume Sibertin-Blanc, 2017, [1]). Thus, at the political level, "extremism" today is understood as a commitment to extreme views and measures (Dictionary of foreign words). One form of full-fledged human activity is "violence" with its destructive and constructive function. However, despite the huge amount of work on the definition of violence, from the famous "midwife of history" (K. Marx) to "malignant aggression" (E. Fromm), while a typology of this term has not yet been developed.

\footnotetext{
* Corresponding author: orlova_vv@mail.ru
} 
Social changes in recent decades have brought not only political relations to the transterritorial level. We are talking about uneven, heterogeneous (in speed and scale) social inclusion and other social institutions (Andrew Ryan Rico, 2015, [2]). The process of the formation of transterritorial systems can be characterized as a natural result of the development of basic social institutions and their self-organization. The complication of the social process, the growth of the scale of social activity leads to the emergence of large institutional formations that determine the leading directions of the development of world society. Integrative processes in today's increasingly complex society are reaching a new level, which has a significant impact on the existence of individual territorial systems (Katarzyna Samson, 2018 [3]; Noah Carl, Francesco C. Billari, 2014, [4]).

Formulation of the problem. Today, the problem of US violence is very relevant (Baltimore, St. Louis, Philadelphia, Washington, DC, Milwaukee, Los Angeles, Chicago, etc.). In the period 2013-2017. more than 1000 incidents of violence in schools were registered, which ultimately can lead to a decrease in confidence, self-esteem, depression and fear. In American sociological discourse, there is experience studying this phenomenon. In particular, the largest American sociologist Ralph Larkin in his study "Understand Columbine" ("Columbine High School massacre") (Breuer, C., Hüffmeier, J., \& Hertel, G., 2016) not only discovered some patterns, but also gave a program to neutralize violence. In 2012, the sociologist Natalie E. Panton, on the basis of online video materials created by Columbine shooters, formulated a set of repeating motifs identifying them as adherents of this group [Halevy, N., Halali, E., \& Cohen, T. R. 2019 ]. For example, a close-up of a weapon, wave a weapon, admiration for the previous arrows. In 2014 these signs were expanded, based on the video of social networks, added such as the timing of the killings, plans to exceed the number of victims. Experts believe that the tragedy affected the subsequent massacres, as it predetermined such actions as revenge, a means of protest, and social isolation (Kazuo Okamura, 2020, [5]).

At present, in Russia, cruelty and aggression are spreading rapidly, incidents in schools related to violence, assault with weapons, and extremist activities have begun to arise (Otradnoye 2014, p. Ivanteevka, Moscow Region 2017, Perm, Ulan-Ude 2017). The authors of the study of extremism in the youth environment note that the main features of extremism are aggressiveness, mass, propaganda of ideas, demosnastrativnost. The object sphere of this study is the scientific and educational complex of Tomsk, as an environment for public dialogue. The subject field is determined by the specifics of the formation of trust / distrust of social agents.

Another factor in the emergence of extremist sentiments in religious communities is the negative reaction to such well-known modern transformations of the way of life of peoples as globalization, Westernization, and digitalization.

The speed of information exchange, mobility of the human masses is constantly increasing, parts of the modern world become more reciprocal and the problems that earlier could remain local and would require relatively simple solutions, today arise simultaneously around the world. This fully applies to extremism and terrorism, and it is obvious that the fight against such phenomena, which threaten security in any part of the world, has become a common task that requires the joint efforts of many States and structures.

Our assumption is that the measure of manifestation of extreme behavior in the youth environment is largely determined by the degree of trust / distrust of social agents, including power structures, and subjects of communication. The purpose of the article is a study of the category of confidence in conditions of social uncertainties, socio-economic changes, and the exacerbation of social contradictions, consideration of the specifics of building trust/distrust of youth to social agents . 
Considering youth as a social phenomenon, we rely on the social-group characteristics of youth. At the same time, the causes of extreme manifestations are rooted in social conditions that give rise to contradictions.

The main sources of empirical data are secondary data from sociological studies of trust and mistrust in government institutions in 2011, 2014. (see: Grigorenko, 2013; Zubok, Grigorenko, Mikheeva, 2013; Zubok, 2014), a survey of 241 students in Tomsk (2015).

In foreign works, the category of "trust" is presented in the context of didactic connections. In the Russian psychological discourse, the phenomenon of "trust" is considered as a relation to one's life in various aspects as an objective and subjective value, includes value, emotional, cognitive, behavioral components and determines the content of human life. Other authors, Sidorenkov A.V., Sidorenkova I.I. Metodiki [consider trust as the main factor of group efficiency when an activity has a jointly interacting organization, which for our study has heuristic potential.

Trust is a community's expectation that its other members will behave more or less predictably, honestly and with attention to the needs of others, in accordance with some general norms (Griffith, A. N. 2016). Societies with a low level of trust are compelled to constantly maintain a certain formal legal basis for ensuring fulfillment of obligations, while societies with a high level of trust are spared from such costs. Social trust is the expectation of reliability from other members of society, which is not associated with specific behavior in a particular situation. This type of social interaction is unambiguously characterized as positive, as it is based on openness, confidence in the decency of a communication partner, and his goodwill.

Such cooperation of individuals is based on a kind of contract system, a contract that can provide strangers with a basis for effective cooperation. However, more effective are organizations and communities in which the interaction of individuals is not regulated in a contractual legal form. Such interconnections are impossible without the existence of some moral community, norms and values shared by all representatives of society, which are the basis of their trust. This is not a return on any rational investment (for example, in the education system), it is the result of the adaptation of the individual in a certain community, the assimilation of the norms existing in him. Social capital is not the achievement of an individual, it is the priority of social virtues over individual. Being in a society with a high level of trust, a person is more trying to prove himself as a member of a group with which he has built trusting relationships, he puts moral principles above economic benefits, thus, social capital is accumulated in society. In a society with a low level of trust, individuals are not inclined to accumulate social capital, and what exists cannot be converted into other forms of capital with maximum benefit. Expectations always contain a projection of the intended result of an interaction, its consequences in the future, as well as values attributed to oneself and other participants in the interaction. These values arise in the process of assessing which actions and reactions will be most effective and adequate to the situation.

The element of trust in any relationship contains certain risks. Modern society is characterized by high rates of development; continuously arising opportunities are not always possible to verify in everyday experience. Confidence in this case acts as a constructive reaction to possible risks. If the scale of the perceived danger seems larger than the degree of protection, trust turns into one of the forms of a protective reaction [Paul R. Ward, Loreen Mamerow, Samantha B. Meyer, 2014, [6]. Australian scientists, exploring the collective actions of football fans, focus on the relationship between people online and offline (Tessa Haesevoets, Chris Reinders Folmer, Alain Van Hiel , 2015, [7]), illustrate the trust of club supporters, emotions, tactics and elements of successful collective mobilization of team supporters.

Sometimes, in the case of a decision on trust, possible negative consequences can be completely ignored. A high degree of trust increases the degree of responsibility for their 
actions and their results, contributes to the development of a creative approach to interpersonal interaction. Trust acts as a mechanism for activating activities in situations of increased complexity for making informed independent decisions within a certain cultural stereotype (Johanna Gereke, Max Schaub, Delia Baldassarri, 2018, [8]). This is a kind of forecasting, a subjective idea of the honesty / dishonesty of another, the hope of a coincidence of expectations and real results. Therefore, trust acts as a property of the subject of trust, the one who displays it, and not the object to which it appears.

From this point of view, trust can be confused with gullibility. Personalized trust acts as a "source of a sense of honesty and authenticity of oneself"; through the mechanism of trust, the threat of "loss of personal meaning" is minimized. We understand trust as the perception of oneself or of another subject, of their actions as correct, true, long-term adherence to this image, which remains until it begins to obviously contradict reality. Confirming many times in everyday life, such installations eventually transform into norms.

One of the manifestations of risk-taking behavior is "extremism". Let us take as a starting point for a sociological study of the phenomenon of "extremism" its understanding as a type of deviant behavior against existing norms and rules shared by the majority in society. The consideration of "extremism" from the point of view of deviation allows us to take into account the main feature - an anti-systemic violent character. Then you can formulate the interpretation of "extremism" - deviant conscious behavior, expressed in calls for action, aggressive actions aimed at denying basic human rights, the desire for public destruction of public order (Meta van der Linden, Marc Hooghe, Thomas de Vroome, 2017 [9]).

Another area of sociological research of the phenomenon of "extremism" is to consider the characteristics of extremism in the context of the social environment: the specifics of manifestation in various areas of social life, group behavior, their environment, intragroup connections, subculture, value orientations, attitudes, stereotypes, etc. In the process of developing sociological knowledge, several approaches to understanding the personality have been formed, among which one can distinguish: the dialectical materialistic approach, according to which the formation of the personality occurs according to the influence of the biological factors of the individual, his social environment, upbringing and self-education.

From the position of an anthropological approach, a person is considered from the point of view of universal properties. The normative approach focuses on the personality traits as a social being related to consciousness and activity. The essence of the sociological approach is the embodiment by an individual of socially significant traits and qualities of a given society. The personalistic approach considers the personality as a combination of a person's mental reactions to the opinions of others, where "I - perception" acts as the mechanism of its formation. Biological and genetic approach, suggests that human behavior is determined by its bioprogram.

By analyzing these approaches, one can formulate personal characteristics based on principles: an extremist personality acts both as an object and subject of biological and social relations, combines the features of the biological kind and social community, has a certain freedom of choice of his behavior, which depends on personal characteristics refracted through social and personal experience.

Given these principles, let us single out the structure of the social level of the extremist personality: actually sociological, which includes motives, goals, interests, life experience; cultural (value orientations, attitudes, norms); moral (morality, morality); internal determinants (needs, interests). The status-role concept enriched sociological knowledge about the individual. Therefore, another important component is the position (place) of an individual in society, revealed through the categories of "social status" and "social role". As for intra-group relations, one of the components is the level of trust / distrust between the members of the group, and personal meaning. 
Trust develops in a three-dimensional space, which includes activity, consciousness and institutions, so trust in the modern sense is a synthesis of their historical formations, the evolution of which proceeds in constant interaction and interpenetration, which causes their progressive complication at each subsequent stage. Instinctive, proto-institutional trust can be characterized as irrational. At a certain stage, modern trust moves to a new level, turning into a rational one: rational arguments contribute to understanding and the emergence of confidence.

Trust in modern society operates at several levels: Confidence in an abstract system (state), which creates the conditions for interaction at an abstract level. Interpersonal trust (network interaction structures). The presence in society of generally accepted values, norms, and rules that ensure the implementation of trust at all levels of the system. Sometimes, using essentially the same criterion, vertical trust (trust in social organizations: government, law enforcement agencies, trade unions) and horizontal (trust in people) are distinguished.

Belgian researchers in a cross-cultural study emphasize the importance of studying the level of scale of political trust and show that the structures of political trust are isomorphic at both individual and country levels. Data from the results of Italian researchers multi-purpose study of households and participation in social networks (SNS) such as Facebook and Twitter prove the impact on the most economically significant aspects of social capital, trust. The authors draw attention to the differences in the accessibility of broadband paths for highspeed Internet, which relates to the technological characteristics of the existing telecommunications infrastructure, determine the types (measures) of trust in others (often referred to as social trust), trust in neighbors (specialized trust) and trust in the police (institutional trust).

\section{Methods}

A secondary analysis of data, the results of the Semistructured interview youth of Tomsk, picks socket (full-time students), sample volume 241 people, 2017, Tomsk.

\section{Results}

The level of information and trust infljuativnogo, action-sovladajushhego level of confidence level of confidentially-protective trust. The obtained data indicate the potential sustainability of youth, but in comparison with other social groups, young people have the greatest dynamics. Due to a change in the conditions of surrounding reality sustainability can shift the focus in the short term in any of the parties. It has been proven that trust is essential for dialogue in society and extreme reduction factor for young people; the trust element in any relationship contains certain risks; the trust acts as a constructive response to possible risks. First of all the students in your social circle included family, friends and odnogrupnikov, followed by work colleagues and least-any associations (Gary Bente, Thomas Dratsch, Kai Kaspar, 2014, [10]).

The willingness of young people in choosing the forms of their activity to be guided by group norms and values, which are sanctioned by public opinion, suggests that institutionally chosen methods are legitimate, and institutions as sources of social patterns inspire confidence. Identification with outgoing meanings means trust on the part of youth. It is trust that ensures the legitimation of social relations, the level of solidarity and the means to achieve goals. The resolution of contradictions caused by dysfunctions of social institutions is recognized by young people as a situation of oppression, leading to uncertainty and the manifestation of extreme signs in behavior. In turn, there is an attitude towards social reality and its objects, expressed in positive categories of trust or in negative categories of hostility 
and distrust. Thus, the level of trust is changing (Lisa M. PytlikZillig, Christopher D. Kimbrough 2017, [11], Kazuo Okamura, Seiji Yamada Editors [12]).

Based on secondary data from sociological surveys in 2011 and 2014. consider the dynamics of indicators of trust in power structures ("Sociocultural mechanism for the formation and reproduction of attitudes towards objects of social reality in Russian society" and "Trust as a phenomenon of social reality") - studies conducted on an all-Russian sample in 13 regions of the Russian Federation in 2011 and in October 2014; the sample size in the first study was 1301 people, the sub-sample of young people aged 18-29 years old was 323 people; in 2014, the total sample was 1459 people, the subsample of young people aged 1529 years was 790 people. ) Integral indicators of youth confidence in power structures exceed similar indicators of distrust: at the end of 2014 constituted President V.V. 37.6\% (trust), $3.9 \%$ (distrust) to Putin, $20.7 \%$ and $10.8 \%$ to the Russian government, respectively. Against this background, youth support for the opposition was weak and amounted to $7.3 \%$, distrust $-20.4 \%$.

At the same time, we note that the very fact of trust in the authorities does not necessarily orient youth towards the support of organizations-supporters of the authorities. So among the supporters of national-patriotic movements, youth are $13.5 \%$, human rights $-9.7 \%, 11.9 \%$ environmental associations. According to the research, the higher the confidence, the more pronounced are the attitudes of young people to social activity. The peculiarities of youth adaptation depend largely on the specifics of the environment with which the subject is forced to interact, because any type of social adaptation is a process of interaction between the individual and the adaptation environment, during which the achievement of compliance of personal characteristics with environmental requirements. The region in this case is considered, first of all, as a result of social self-organization, a process relatively autonomous from the process of state regulation. It is in this quality, the quality of the product of selforganization, that the unity of the geographical and symbolic (mentally mastered) territory comes to the.

The success of the integration and disintegration of young people in the social environment depends on two most important factors: the individual characteristics and the environment in which the real process of adaptation is carried out. The development of a sense of patriotism and social capital in society are closely related, because the basis for their formation is the growth of trust in society and the establishment of social ties. The basis for the maturation of a sense of patriotism is the acquisition of a stable identity, which is supported by the existing social capital in society: ties based on trust between individuals and groups.

The images of perception that have developed in the process of the adaptation process allow the individual to construct and modify in his consciousness the ideal models and images of the world around him. Identity is multidimensional and procedural. In the context of modernity, two interdependent and, at the same time, multidirectional identification processes should be distinguished: globalization and localization. If globalization strengthens the national and cosmopolitan types of identification, then localization - local and ethnic types. One of the most important sources of social capital and adaptation agents.

One of the most important sources of adaptation agents in modern societies is the educational system. Schools and universities not only provide students with knowledge and skills, but also try to contribute to their socialization in certain cultural traditions. Education generates social capital in various ways, as students become familiar with the social norms of their profession or specialty, so the adult part of the population is better socialized. In the case of individual companies, social capital can be cultivated deliberately through direct investment in education and corporate skills training, which is a way of socializing company employees through a set of norms that increase the willingness to cooperate with each other 
and generate a sense of group identity (Fabio Sabatini, Francesco Sarracino, 2018 [13]; Joseph A. Hamm, Corwin Smidt, Roger C. Mayer 2019, [14]).

An analysis of experts' answers about the trust of young people in the environment, understanding of the strategies of patriotism as a counterbalance to extremism made it possible to identify two types of functions for society: "patriotism as protection", "patriotism - trust / distrust".

\section{Head of a rural settlement}

"What, in your opinion, does" being a patriot "mean today? To feel your country, to be one whole place where you live. Feel that you are one of those people living in this country, city, area. The unity of all. empathy with your friend.

What is the significance of patriotism for the life of the people, the state. What does patriotism give to a person, to society? The meaning for the people is a sense of protection. The state grows stronger if all are united. Patriotism does not only mean to praise, but also to criticize it. It gives a person the feeling that you are not alone, you are a part of this mechanism. Society gives unity, direction, the ability to build something new.

\section{Member of the Youth Parliament}

Today patriotism has acquired a hypertrophied character. And it seems to me that a patriot is still a person who loves his homeland and country, but is patriotism that the mass media is trying to impose on us.

What is the significance of patriotism for the life of the people, the state. What does patriotism give to a person, to society? . I consider it a very vivid example when patriotism really raised the country - these are the post-war years. When the Soviet Union rose from its knees precisely due to the idea, due to the love of people for their country. That is, these are quite related concepts that people, in spite of themselves, raised their country. This is the strongest example in my opinion...

\section{Chief Specialist of the Youth Policy Department}

What is the significance of patriotism for the life of the people, the state. What does patriotism give to a person, to society?

Patriotism is very important for the climate in society. Patriotism gives you the feeling that you are in your place. Among the right people with whom you share a great history. But it is impossible without a sense of security and satisfaction.

According to the results of the study among TUSUR students, the level of trust is at a stable average level (2014, Tomsk, questionnaire method, nest sample (full-time students), $\mathrm{n}$ $=241$ people). The calculation was carried out for such coefficients as the level of confidential and protective trust (RCD), the level of informational-influenative trust (IID) and the level of activity-co-trusting trust (DSD) (met. A. Sidorenkov). The ratio of the coefficients of RCD, IDN and DSD for the group as a whole and among those with whom close relations are maintained fluctuate slightly, quite close to 1 . This suggests that the level of trust in relations in the whole group is not too different from those with who maintains close relations (the stronger the indicator approaches 1 , the smaller the difference). In other words, students trust people from their social circle as a whole, as well as those with whom they maintain close relationships, i.e. this indicator is approaching a common denominator. 


\section{Discussion}

The indicators of the adjusted group coefficients KOD and DSD fall into the range of average values, this suggests that students generally neutralize the moral and ethical appearance of others, their integrity, the ability to effectively contribute to the overall work, the possibility of cooperation in its implementation. In addition, there is no personal closeness, but there is also no special desire to open to others - an average level is maintained, albeit steady.

An indicator of informational-influenative trust (adjusted coefficient) is higher than average in the student's environment: a tendency to high exists both in a close circle of communication and in general. This means that students are prone to a positive assessment of someone else's opinion, belief in their correctness, have a good indicator of information openness, i.e. able to perceive from others not only information but also influence. However, this may be due not so much to the presence of a high level of tolerance in the student environment, but to the psychological characteristics of the age group: the young man's consciousness has a special sensitivity, the ability to process and absorb a large flow of information. During this period, critical thinking develops, the desire to give one's own assessment of various phenomena, the search for argumentation, an original solution, but at the same time, the influence of attitudes and stereotypes of previous generations remains.

In general, the data of the first part are comparable with the data obtained during the second part of the study: $23 \%$ trust most of their circle of friends, about half - $31 \%$, a small group - $22 \%$ and the closest $-23 \%$. $21 \%$ can turn to the majority for help, about half of the representatives of their circle of friends $-27 \%$, to a small group - $28 \%$, to the closest ones $25 \%$. According to the results of the second part of the study, $6 \%$ discuss their plans with many from their circle of friends, about half with $36 \%$, with a small group - $30 \%$, only with close ones $-29 \%$. Thus, high and above average confidence levels and below average and low levels are represented among students in the ratio of about 50 to 50 . Such a neutral position, on the one hand, can be characterized by potential stability. But young people in comparison with other social groups have the greatest dynamics, because of which, due to changes in environmental conditions, the emphasis in a fairly short period of time can shift to either side. Therefore, it is necessary to try to direct this process in a positive direction.

The following can be said about the inclusion of students in various social groups: about half of the students rate their circle of communication wider than average: $22 \%$ as "wide", $20 \%$ as "rather wide", 35 as "average". It must be clarified that the breadth of the circle of friends as a whole does not depend on whether the student is a resident of Tomsk or a nonresident.

First of all, students include family, friends and classmates in their social circle, then work colleagues, and lastly, any associations and unions. A similar distribution of priorities in communication is characteristic of young people, who in this period of life are most affected by family and peers. In addition, the sample consisted of full-time students, for whom employment is associated with difficulties associated with combining work and studies. However, the main indicator of the level of trust is called inclusion in various communities. From this point of view, we can conclude that in the student community the level of trust is not sufficiently developed. This is evidenced by the extremely low indicator of trust in associations, networks, associations - only $4 \%$ of those polled trust them. The absolute majority primarily trusts such groups as family and friends ( 74 and $77 \%$, respectively). At the same time, students with a "wide" circle of communication tend to trust most and about half. The closest people trust, as a rule, students with a narrow circle of communication. 


\section{Conclusions}

Work on expanding the circle of acquaintances among students is not in the nature of vigorous activity. In $60 \%$ of cases, everything happens by itself, in addition to the will of the individual: enrollment in a particular group, checking into a dorm room, etc. $29 \%$ of students do this sporadically, and only $7 \%$ actively and systematically work to expand the circle of acquaintances, $4 \%$ of respondents take a passive position.

Despite the low activity with regard to expanding their circle of contacts, the intensity of connections within it, according to the students themselves, is rather high: $66 \%$ of students often meet people from their circle of contacts, and quite often they initiate such meetings (62\% of respondents).

Thus, the following conclusions can be drawn: trust is the most important condition for dialogue in society and a factor in reducing the extremeness of youth; the element of trust in any relationship contains certain risks; trust acts as a constructive response to possible risks. I $n$ the student community, the level of trust is not sufficiently developed.

As part of the counter-terrorism measures currently being announced by many States, we need jointly coordinated legislative actions that prevent or limit the possibility of terrorist actions, as well as ways to hide the perpetrators of terrorist acts.

It is necessary to reveal the anti-human nature of radical ideas of extremism that justify terrorist actions through targeted propaganda, that is, to conduct a total struggle for minds. Here, the educational and educational functions of society come to the fore, when special "anti-extremist subjects"should be introduced at all levels. (Margaret C. Wardle, Daniel A. Fitzgerald, Michael Angstadt, Chandra S. Sripada, Kevin McCabe, K. Luan Phan 2013, [15]).

In our opinion, such educational activities should be carried out to the greatest extent in the student environment, since student life is full of interpersonal contacts, and at the same time - between individuals of various lifestyles, representatives of different ethnic groups and, very often, different faiths. Unfortunately, young people are not always well-informed in matters of their own and other religions. often, young minds have a biased attitude to other faiths, distorted ideas about the culture and history of the peoples who created these cults. Therefore, it is difficult to find a better place to teach the younger generation the principles of tolerance, the basics of interfaith communication, the ability to establish communication for cooperation, etc.

In conclusion, we emphasize the importance of protecting the spiritual security of both individuals and any communities, including large States, countering the destructive potential of extremism, and the need for a special youth policy aimed at the spiritual and moral development of individuals brought up on the principles of inter-ethnic, inter-confessional communication and cooperation, while at the same time being able to put barriers in the way of aggressive radical ideas and influences. These goals are set today by such organizations of the world community as the United Nations, UNESCO, and the parliaments of many States, including the Russian Federation, and to achieve them, the efforts of both state bodies and science are necessary

\section{References}

1. P. Bojanić, G. Sibertin-Blanc, De la terreur à l'extrême violence (OpenEdition Books, 2017) DOI:10.4000/books.europhilosophie. 153

2. A. Ryan Rico, The University of Texas at Austin Fans of Columbine shooters Eric Harris and Dylan Klebold (2015) DOI: https://doi.org/10.3983/twc.2015.0671 
3. K. Samson, Trust as a mechanism of system justification (2018) https://doi.org/10.1371/journal.pone.0205566

4. N. Carl, F.C. Billari, PLOS ONE (2014) https://doi.org/10.1371/journal.pone.0091786

5. K. Okamura, S. Yamada, Adaptive trust calibration for human-AI collaboration (2020) https://doi.org/10.1371/journal.pone.0229132

6. P.R. Ward, L. Mamerow, S.B. Meyer, Interpersonal Trust across Six Asia-Pacific Countries: Testing and Extending the 'High Trust Society' and 'Low Trust Society' (2014) https://doi.org/10.1371/journal.pone.0095555

7. T. Haesevoets, C. Reinders Folmer, A. Van Hiel, Is Trust for Sale? The Effectiveness of Financial Compensation for Repairing Competence-versus Integrity-Based Trust Violations (2015) https://doi.org/10.1371/journal.pone.0145952

8. J. Gereke, M. Schaub, D. Baldassarri, Ethnic diversity, poverty and social trust in Germany: Evidence from a behavioral measure of trust (2018) https://doi.org/10.1371/journal.pone.0199834

9. M. van der Linden, M. Hooghe, T. de Vroome, Extending trust to immigrants: Generalized trust, cross-group friendship and anti-immigrant sentiments in 21 European societies (2017) https://doi.org/10.1371/journal.pone.0177369

10. G. Bente, T. Dratsch, K. Kaspar, PLOS ONE 9(8), e107075 (2014) https://doi.org/10.1371/journal.pone.0107075

11. L.M. PytlikZillig, C.D. Kimbrough, E. Shockley, A longitudinal and experimental study of the impact of knowledge on the bases of institutional trust (2017) https://doi.org/10.1371/journal.pone.0175387

12. Kazuo Okamura, Seiji Yamada, PLOS ONE 15(2), e0229132 (2020) https://doi.org/10.1371/journal.pone.0229132

13. F. Sabatini, F. Sarracino, Social Indicators Research 4, 1-32 (2018) http://www.socialcapitalgateway.org/sites/socialcapitalgateway.org/files/data/paper/20 18/04/08/101007s11205-018-1887-2published.pdf

14. J.A. Hamm, C. Smidt, R.C. Mayer, Understanding the psychological nature and mechanisms of political trust (2019) https://doi.org/10.1371/journal.pone.0215835

15. M.C. Wardle, D.A. Fitzgerald, M. Angstadt, C.S. Sripada, K. McCabe, K. Luan Phan, The Caudate Signals Bad Reputation during Trust Decisions (2013) https://doi.org/10.1371/journal.pone.0068884 